\title{
Novel wireless sensors for in situ measurement of sub-ice hydrologic systems
}

\author{
E.A. BAGSHAW, ${ }^{1}$ B. LISHMAN, ${ }^{2}$ J.L. WADHAM, ${ }^{1}$ J.A. BOWDEN, ${ }^{3}$ S.G. BURROW, ${ }^{3}$ \\ L.R. $\mathrm{CLARE}^{3}$ D. CHANDLER ${ }^{1}$ \\ ${ }^{1}$ Bristol Glaciology Centre, School of Geographical Sciences, University of Bristol, Bristol, UK \\ E-mail: liz.bagshaw@bristol.ac.uk \\ ${ }^{2}$ Institute for Risk and Disaster Reduction, University College London, London, UK \\ ${ }^{3}$ Queens School of Engineering, University of Bristol, Bristol, UK
}

\begin{abstract}
Wireless sensors have the potential to provide significant insight into in situ physical and biogeochemical processes in sub-ice hydrologic systems. However, the nature of the glacial environment means that sensor deployment and data return is challenging. We describe two bespoke sensor platforms, electronic tracers or 'ETracers', and 'cryoegg', for untethered, wireless data collection from glacial hydrologic systems, including subglacial channels. Both employ radio frequencies for data transmission, are designed to endure harsh environmental conditions and can withstand low temperatures, high pressure, turbulence and abrasion. We discuss the design, optimization and field testing of the ETracers and cryoegg, culminating in test deployments beneath the Greenland ice sheet. The small, low-cost ETracers were able to travel through subglacial drainage channels, from where they returned water pressure measurements through $100 \mathrm{~m}$ of ice, and could measure water depth in crevasses. The larger cryoegg was able to return multi-parameter data from moulins through $500 \mathrm{~m}$ of wet ice to receivers up to $2 \mathrm{~km}$ away, and from $12 \mathrm{~m}$ depth in a proglacial lake to a receiver on the shore. The tests demonstrate that the cryoegg and ETracers are low-power, versatile, robust wireless sensor platforms suitable for glacial environments, which may be used with portable, low-cost receiving equipment.
\end{abstract}

KEYWORDS: basal melt, glacier hydrology, glaciological instruments and methods, subglacial lakes

\section{INTRODUCTION}

Water at the bed of glaciers is a key factor controlling the response of ice to stress and strain (Weertman, 1972; Engelhardt and Kamb, 1998), and its potential as a host for subglacial microbial communities (Skidmore and others, 2000; Lanoil and others, 2009). Various methods have been employed to determine the flow path characteristics of water at the bed of glaciers, including dye tracing (Nienow and others, 1998), gas tracing (Chandler and others, 2013), borehole drilling (Engelhardt and others, 1990; Hubbard and others, 1995; Fountain and others, 2005; Meierbachtol and others, 2013) and direct observations using sensors (Hart and others, 2006; Smeets and others, 2012). These techniques have enabled invaluable observations of subglacial and englacial conditions. They have in turn validated theories of glacier motion (Blake and others, 1994; Harper and Humphrey, 1995; Willis, 1995; Engelhardt and Kamb, 1998) and response to surface melting (Bartholomew and others, 2011; Chandler and others, 2013; Doyle and others, 2013; Meierbachtol and others, 2013) and allowed the examination of subglacial microbial communities (Priscu and others, 1999; Skidmore and others, 2000; Christner and others, 2012). However, data collected by such techniques are limited to single points, where the sensor is implanted or the borehole intersects the bed, or, in the case of dye, gas or hydrochemical measurements, to bulk inferences about the characteristics of the entire drainage system between the tracer injection and recovery sites. In order to fully understand the subglacial environment, a technique is required that can take measurements at a variety of locations beneath the ice.
Wireless sensors can be used for this purpose: for example, the Glacsweb program implanted a number of sensor 'nodes' beneath the ice at glaciers in Norway and Iceland which returned data to a base station on the ice surface (Hart and others, 2011; Martinez and Basford, 2011), and the WiSe subglacial pressure sensor was used to transmit pressure data to the surface from several boreholes beneath the Greenland ice sheet (Smeets and others, 2012). Data collected by these sensors were limited to the immediate locations where they were implanted. Since subglacial meltwater channels are the focus of much scientific interest, it would be useful to utilize wireless sensing techniques to collect in situ data throughout the drainage network. There have been a few examples of the use of wireless sensors to collect data in subglacial water channels (Behar and others, 2008; Bagshaw and others, 2012). However, they have been limited by reliance on the emergence of the sensor platform from beneath the ice to return data, either by manual recovery (Bagshaw and others, 2012) or by data transmission via an Iridium satellite modem (Behar and others, 2008). The tortuous nature of the subglacial drainage system frequently causes sensor entrapment or entrainment, and hence, data return can be unreliable. An alternative method for more reliable data recovery is required, that still allows the sensor to travel untethered through subglacial water channels. Here we describe the development and testing of two wireless sensor platforms, a 'cryoegg' and an updated version of the electronic tracer or 'ETracer' (Bagshaw and others, 2012), for the collection of along-flow-path data beneath glaciers and ice sheets, together with protocols for communicating data to receivers at the ice surface. 


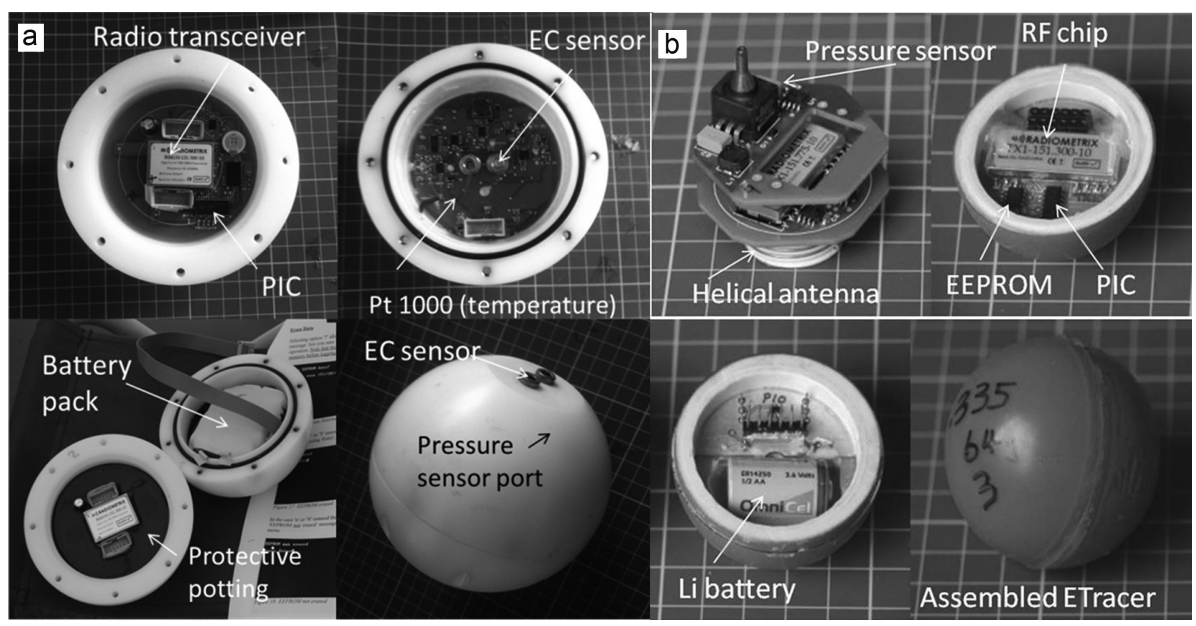

Fig. 1. Cryoegg (a) and ETracer (b) sensor platforms in various stages of assembly. For scale, the background grid is $1 \mathrm{~cm}^{2}$.

The wireless communications strategy for the sensor platforms is radio frequency (RF). RF is a recognized technique for transmission through ice. Radar systems have been used since the 1950s to measure the thickness of ice sheets (Evans, 1963) and to understand the distribution of water beneath ice sheets (Oswald and others, 2008). Radioecho sounding (RES) has been widely employed for imaging the subsurface, where energy pulsed from a transmitter above the ice travels down through the ice and is reflected back to the surface by internal layers and other reflectors, then detected at the ice surface. The timing and signal strength of reflections allow inferences to be made about the ice characteristics and the subglacial environment. More recently, high-frequency $(\mathrm{HF} ; 30 \mathrm{MHz})$ and ultra-highfrequency (UHF; $433 \mathrm{MHz}$ ) radio signals have been used to return data wirelessly from probes located in the subglacial environment (Hart and others, 2006; Smeets and others, 2012). In both cases, the probes were tethered or remained in a single location and were not deployed freely into the hydrological system. Here we investigate the use of RF transmission for wireless data transfer from subglacial channels by testing different frequencies and receiver configurations to determine the optimum transmission scenario for the sensors. We go on to test the optimized cryoegg and ETracer sensor platforms in ice and meltwater environments on and within the Greenland ice sheet.

\section{SENSOR PLATFORM DESIGN}

In order to fulfil our goal of collecting data from glacial meltwaters, the RF-equipped wireless sensor platforms must be capable of operating at low temperatures, be able to travel through the subglacial water channels, and be capable of data transmission through water and ice while in motion. The platforms must be able to:

$$
\begin{aligned}
& \text { easily access the subglacial environment; } \\
& \text { withstand environmental stresses; } \\
& \text { have sufficient power to enable sustained operation for } \\
& \text { periods of days to months; }
\end{aligned}
$$

return data to the surface without a physical connection.

We designed two RF-equipped sensor platforms to meet these requirements: a 'cryoegg', and a smaller 'ETracer'. The
ETracer (Bagshaw and others, 2012) is a single-parameter platform which houses one sensor. It is smaller, lower-cost and more mobile than the cryoegg, but has lower transmission capabilities. The cryoegg has a higher payload which can house several sensors, and is capable of transmitting greater volumes of data. Here we outline how the cryoegg and ETracers meet the design priorities presented above.

\subsection{Access to the subglacial environment}

Sensors have previously been implanted into the subglacial environment via boreholes (Hart and others, 2006; Smeets and others, 2012). However, this is frequently expensive and there is no guarantee of intersecting a subglacial drainage channel (Hubbard and others, 1995). An alternative method, which is applicable to most temperate glaciers and in the lower reaches of the Greenland ice sheet, is to use moulins to directly access subglacial drainage channels (Bagshaw and others, 2012). The platform must therefore be sufficiently compact to allow direct deployment into moulins, and of a suitable shape to travel within meltwater flows.

\subsubsection{Design solution}

The ETracer and cryoegg are spherical, to allow transit through englacial drainage routes (Fountain and others, 2005; Gulley and others, 2009, 2012) and easy motion along the glacier bed. The cryoegg was $120 \mathrm{~mm}$ in diameter, while the ETracer was $50 \mathrm{~mm}$ (Fig. 1). The ETracers were designed to pass through very small subglacial passages, whereas the cryoegg could become lodged at the point where channels narrow and return multiple data transmissions from each position. Both sensors can be deployed without specialist equipment.

\subsection{Environmental stresses}

The subglacial environment is subject to high pressure (Iken and Bindschadler, 1986), high sedimentation (Walder and Fowler, 1994), abrasion (Haldorsen, 1981) and turbulent water flows (Kor and others, 1991). The sensor platform must therefore be robust, waterproof and able to withstand such stresses (high normal load, abrasion and impact stress), while allowing on-board sensors to make contact with the subglacial water to take measurements. The sensors used must also be suitable for the glacial environment, and hence able to function at low temperature and in low ionic strength waters. 


\subsubsection{Design solution}

The cryoegg was manufactured from Delrin plastic, a polyoxymethylene polymer characterized by high strength, hardness and rigidity. The sphere was $120 \mathrm{~mm}$ in diameter and machined in two halves on a CNC lathe (Fig. 1a). Bespoke sensor ports were added, according to the sensor suite in use. Sensors and electronic components (Fig. i: supplementary material at http://www.igsoc.org/hyperlink/ 65a007/suppinfo_figi.gif) were mounted in the sphere using an epoxy resin compound (Sicomin) to fix components in place during transit and prevent damage on impact. The printed-circuit boards (PCBs) and batteries were sealed with a rubber potting compound (Raytech RTV), which provided additional shock protection. Finally, the two halves of the sphere were screwed together using eight external screws, and watertightness was maintained with an O-ring seal. The ETracer was formed from a $50 \mathrm{~mm}$ diameter acrylic mould in two halves, strengthened by three layers of acrylic paint (Fig. 1b). PCBs, sensors and electronic components (Fig. ii: at http://www.igsoc.org/hyperlink/65a007/suppinfo_figii.gif) were mounted in place using epoxy resin (Sicomin) whose density was adjusted with the addition of glass microspheres. The two spheres were fixed together immediately prior to deployment using a two-part adhesive.

The ETracers contained a single pressure sensor (Honeywell 40PC) with a range of $0-250 \mathrm{psi}$ (operating range 0-1.8 MPa, equivalent to $180 \mathrm{~m}$ head of water; absolute maximum pressure 3.4 MPa). The port was fixed to the outside of the sphere. The same sensor was also used in the cryoegg, alongside electrical conductivity (EC) and temperature sensors. EC was measured using a voltage divider across two stainless-steel electrodes mounted in the shell that were excited by a $500 \mathrm{~Hz}$ square wave. A platinum wire Pt1000 sensor (Fenwall) was embedded into one of the EC electrodes to measure water temperature. The EC sensor was calibrated in low ionic strength solutions $(\mathrm{KCl}$ solutions of varying strength, equivalent to $0.5-50 \mu \mathrm{S} \mathrm{cm}^{-1}$ ), and the temperature sensor was configured for maximum sensitivity between $-2^{\circ} \mathrm{C}$ and $+2^{\circ} \mathrm{C}$. These sensors were selected for functionality tests and to measure basic meltwater properties at the bed of the test glacier, but the ETracer and cryoegg may be configured for other small sensors.

\subsection{Power requirements}

The sensor platforms must support sufficient battery power to run the sensing, microprocessing, memory and data transmission systems for the duration of planned deployment. The data transmission, in particular, is likely to be a significant drain on power resources. The battery capacity is nevertheless limited by the size and shape of the package, so compromises must be reached between platform function and longevity.

\subsubsection{Design solution}

A bespoke PCB was manufactured to mount the sensors, memory, power and transmission components in both the cryoegg and ETracer. The cryoegg was powered by four AAsize lithium batteries (EVE 14505M) capable of supplying a continuous current of $400 \mathrm{~mA}$ with pulses of up to $1000 \mathrm{~mA}$, whereas the ETracer was limited to a $1 / 2 \mathrm{AA}$ sized lithium battery (EVE ER14250T). Sensor data logging was coordinated by PIC18F2523 (cryoegg) and PIC16F688 (ETracer) 8-bit microcontrollers which managed power-saving sleep modes, and all data were stored on $512 \mathrm{~Kb}$ EEPROM
(25AA512). Timekeeping within the cryoegg was managed with a Maxim Integrated real-time clock (DS3234), with battery backup provided by a separate lithium coin cell. In order to conserve power and to coordinate the episodic measurement cycle, the microcontrollers were periodically woken from deep sleep with interrupts generated from ultralow-power timers (Fig. iii: supplementary material at http:// www.igsoc.org/hyperlink/65a007/suppinfo_figiii.gif). This was achieved with the real-time clock in the cryoegg, while ETracers utilized the microcontroller's inbuilt ultra-lowpower oscillator. The cryoegg was configured to collect burst samples of EC, temperature $(T)$ and pressure $(P)$ every $10 \mathrm{~min}$ and a moving average filter applied. The smoothed data from 40 samples were saved to the internal memory, with an associated time stamp from the internal clock. Data were transmitted using a $500 \mathrm{~mW}$ radio transceiver (Radiometrix $\mathrm{BiM} 1 \mathrm{H}$ ) with a helical antenna, formed from a length of pipe and wire. A helical antenna configuration could easily fit into the sensor platform packaging, and be specifically tuned for optimum performance in fresh water. The antenna length for both the ETracers and the cryoegg was determined by signal strength testing in shallow freshwater bodies in the UK. In the ETracers, all data were written to the EEPROM and the mean and maximum data points stored in the memory were transmitted using a $50 \mathrm{~mW}$ radio transmitter (Radiometrix TX1). Both the ETracers and cryoegg could be configured to adjust sampling, radio beacon and data transmission intervals via PC, with UART communications running a terminal emulator with a text-based user interface. Radio transmissions of data from the cryoegg were configured to transmit at specific intervals four times daily. Data redundancy ensured that any missed transmissions could be recovered at other times during the next day. The egg could also be configured to run in a 'calibration mode' (Fig. iv: supplementary material at http://www.igsoc.org/hyperlink/ 65a007/suppinfo_figiv.gif), which polled the sensors and transmitted data more frequently.

\subsection{Wireless data return}

To allow the sensor platforms to 'roam' and collect data from distributed locations at the glacier bed, data must be returned to the surface wirelessly. Previous testing has shown that RF communication is effective in ice (Hart and others, 2006; Smeets and others, 2012), although only when the water content is low (Lishman and others, 2013). The optimum frequency depends on a number of factors, namely the ice texture, the required range and the antenna size. Radio attenuation in ice and water rises with increasing frequency, which suggests that lower frequencies will lead to improved transmission ranges. Counteracting this, the antenna efficiency that can be achieved within a given volume (in this case, within the sensor package) increases with increasing frequency. A compromise must therefore be reached between transmission range and antenna size. The radio transmitter must have sufficient power to overcome attenuation caused by wet, heterogeneous ice, and the receiving equipment on the ice-sheet surface or adjacent rock outcrops must be small and portable to account for the movement of the sensors through the subglacial drainage system.

\subsubsection{Design solution}

The widely used amateur radio bands, 151 and $433 \mathrm{MHz}$ (also known by their wavelengths, $2 \mathrm{~m}$ and $70 \mathrm{~cm}$ ), were 
selected for the sensors, since they represent pragmatic solutions for antenna sizing, and a range of off-the-shelf equipment is available. Data were transmitted via RF in binary format. The RF communications scheme for the cryoegg consisted of a twice-daily RF chirp that comprised 10 byte packets including a time stamp, sensor identification (ID) and $15 \mathrm{~min}$ averaged EC, $T$ and $P$ data. Each chirp was transmitted using frequency shift keying, which produced a two-tone binary representation of the ASCII characters stored on the internal memory. The high (151 or $433 \mathrm{MHz}$ $+2.25 \mathrm{KHz}$ ) and low $(151$ or $433 \mathrm{MHz}+1.75 \mathrm{KHz})$ tones were also used to create an individual Morse-coded chirp to detect and identify the sensor with an ID number. In order to conserve power, data were only transmitted twice daily, although the sensor ID chirp occurred every 15 min. Data were broadcast at $300 \mathrm{bps}$, which meant each packet took $3.3 \mathrm{~ms}$ to transmit. A whole day of data could hence be transmitted in $40 \mathrm{~s}$. Data transmissions were Manchester encoded to ensure a d.c.-free (zero mean) transmission, improving signal interpretation at the receiver end. Each chirp began with starting characters specific to each egg, so each individual sensor could be identified by both the ID chirp and data stream. In the lower-power-equipped ETracers, only summary statistics were transmitted, to conserve the battery. The sensor ID, and maximum and mean pressure stored on the internal memory were broadcast every $30 \mathrm{~s}$.

Transmitted data were received using a WinRadio G305 or G315 software radio and netbook, or a Biotrack Sika radio tracking receiver coupled to a Sony audio recorder. Both receivers used a Yagi antenna, which gave the best performance when mounted or held horizontally with the elements perpendicular to the ground. The Sika receiver was extremely portable and optimized for field operation, but the output must be recorded using a separate audio recorder which was less rugged, and which required additional processing to extract the audio data. The WinRadio system required a $\mathrm{PC}$ for operation, which limited its longevity and portability, but the use of a low-power netbook or tablet and weatherproof housing allowed unattended deployment of the system on the glacier. The strength of the received audio stream was measured using a software s-meter, which was programmed to record the signal strength $(\mathrm{dBm})$. The encoded intermediate-frequency (IF) output of the receivers was recorded as a WAV file by either the WinRadio or the audio recorder, and subsequently decoded. Real-time demodulation of the signal was achievable, using a custom-written GUI, but data extraction was possible at a lower signal-to-noise ratio when using offline demodulation.

\section{DESIGN OPTIMIZATION}

\subsection{Low-temperature testing}

The prototype cryoegg and ETracers were leak-tested in a water tank at the University of Bristol and then subjected to freeze-thaw cycling between $-10^{\circ} \mathrm{C}$ and $10^{\circ} \mathrm{C}$ for several days. The batteries were subjected to $-10^{\circ} \mathrm{C}$ and power output was measured, and overall consumption was determined by the frequency and length of data transmissions. Further environmental tests were conducted in situ during deployment at Leverett Glacier, southwest Greenland, in August 2012 and at Kiattuut Sermiat, Narsarsuaq, South Greenland, in August 2013 (see below).

\subsubsection{Results}

Sensor performance was adequate in all trials, with both platforms and all sensors remaining operational during freeze-thaw and leak testing. The cryoegg EC sensor showed good sensitivity to a range of different low ionic strength solutions $\left(\mathrm{KCl}, \mathrm{NaCl}\right.$ and $\mathrm{NaHCO}_{3}$ ranging from 2 to $50 \mu \mathrm{S} \mathrm{cm}^{-1}$ ). Battery voltage remained at $3.6 \mathrm{~V}$ during sleep and $3.1 \mathrm{~V}$ during transmit modes throughout the 67 hour test. Platform lifetime was dependent on the length and frequency of transmissions. If the entire data stream was transmitted twice daily, tests at $0^{\circ} \mathrm{C}$ indicated that the cryoegg had sufficient power for 100 days of continuous operation. Transmitting summary statistics every minute, rather than the entire data stream, meant that the ETracers could also run continuously for up to 100 days despite the smaller battery. Lifetime of both platforms could be extended by reducing the number of daily transmissions.

\subsection{Frequency selection}

The received signal strength from a subglacial radio transmitter is largely controlled by geometric spreading $G$ and dielectric attenuation L (Matsuoka and others, 2012). For one-way transmission, using the decibel scale $\left([x]_{\mathrm{dB}}=\right.$ $\left.10 \log _{10} x\right)$, the received power $P_{\mathrm{R}}$ will be

$$
\left[P_{\mathrm{R}}\right]_{\mathrm{dB}}=\left[P_{\mathrm{T}}\right]_{\mathrm{dB}}+[S]_{\mathrm{dB}}-[G]_{\mathrm{dB}}-[L]_{\mathrm{dB}}
$$

where $P_{\mathrm{T}}$ is the transmitted energy and $S$ is a system gain, incorporating the antenna gains (Eqn (1)). Geometric spreading $(G)$ is a function of the path length and the relative permittivity, and $L$ is the loss due to dielectric attenuation. If the majority of the signal path is below the firn, variations in relative permittivity affect $G$ very little, and so variability in overall system range is controlled by dielectric attenuation. The dielectric attenuation is known to be highly dependent on ice temperature and on the presence of impurities in the ice. In Antarctica the attenuation in the ice interior at typical radar frequencies has been modelled at $\sim 10 \mathrm{~dB} \mathrm{~km}^{-1}$, while in ice streams and in ice overlying subglacial lakes it can vary from 0 to $30 \mathrm{~dB} \mathrm{~km}^{-1}$ (Matsuoka and others, 2012). Field experiments support this modelling, with an observed attenuation of $1-40 \mathrm{~dB} \mathrm{~km}^{-1}$ dependent on temperature and geography (Barwick and others, 2005), and also show a clear increase in attenuation with transmission frequency, in the range $100 \mathrm{MHz}$ to $1 \mathrm{GHz}$.

Measured attenuation in pure ice can be roughly estimated. However, for the applications described in this paper, the signal path may often include other media (e.g. sediment, gas bubbles, water and solute). The signal suffers comparatively little attenuation in air, but attenuation in water can vary from $0.1 \mathrm{~dB} \mathrm{~m}^{-1}$ in fresh water to $1000 \mathrm{~dB} \mathrm{~m}^{-1}$ in salt water (Zirizzotti and others, 2010). Power losses will also occur as a result of reflection at ice/water and ice/air interfaces, and these are likely to be of the order of $3 \mathrm{~dB}$ at each interface (Peters and others, 2005). To compare attenuation in ice at the selected frequencies, 151 and $433 \mathrm{MHz}$, field tests were conducted $30 \mathrm{~km}$ from the southwest margin of the Greenland ice sheet at $66^{\circ} 56^{\prime} 06^{\prime \prime} \mathrm{N}, 48^{\circ} 49^{\prime} 02^{\prime \prime} \mathrm{W}, \sim 60 \mathrm{~km}$ east of Kangerlussuaq, in August 2011. RF data were transmitted through varying distances of ice, and received signal strength measured. A signal comprising three $1 \mathrm{~s}$ tone outputs every $20 \mathrm{~s}$ was sent from a $1 \mathrm{~W}$ Quansheng TG-UV2 handheld radio at both frequencies. The received signal strength, as a function of the 


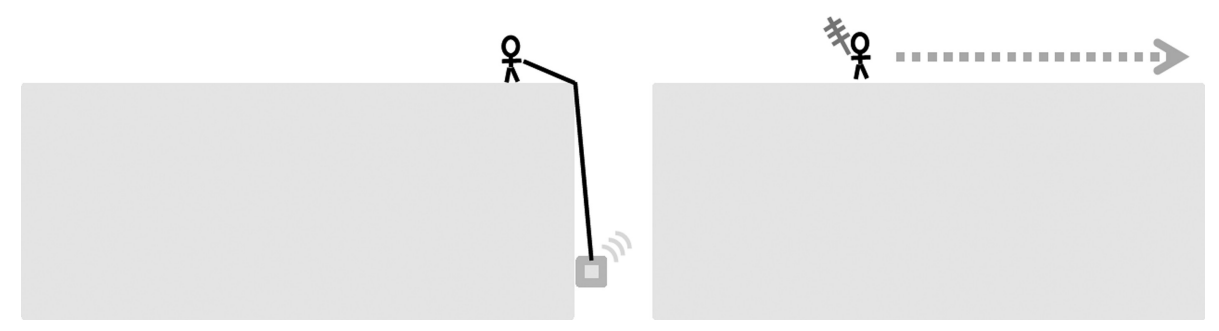

Fig. 2. Schematic of the frequency tests, where the transmitter was suspended into a moulin while the handheld receiver and antenna were gradually moved across the ice surface. Received signal strength was recorded up to $2 \mathrm{~km}$ from the moulin.

experimental geometry, was measured by lowering the transmitter into a moulin and moving the receiver across the glacier surface (Fig. 2). The apertures of the moulins were 1-2 $\mathrm{m}$ in each experiment. Horizontal distances were measured by handheld GPS, which means there were potential errors of $\pm 3 \mathrm{~m}$ in the location of any individual point. Vertical distance into the moulin was measured using marks on the rope used to lower the transmitter, and was accurate to $\pm 5 \mathrm{~cm}$.

\subsubsection{Results}

In experiments at both 151 and $433 \mathrm{MHz}$, significant signal attenuation was observed as distance was increased (Fig. 3). We assume that the majority of the signal took a direct path through the ice from the transmitter to receiver, but it may also have travelled through the air: via the test borehole and over the ice surface to the receiver. Two simple models were fitted to the field data; the first assumes that all signal energy is conserved, and so the signal power decreases as the square of the distance from the transmitter. A slightly more realistic model allows that as well as this $r^{-2}$ decay, the signal is attenuated by some fixed fraction per unit of distance (and convenient units for this attenuation are $\mathrm{dB} \mathrm{m}^{-1}$ ). These models are overlaid on the experimental data in Figure 3. The minimum mean squared error between results and predictions is with an attenuation of $0.18 \mathrm{~dB} \mathrm{~m}^{-1}$ for $151 \mathrm{MHz}$ and $0.22 \mathrm{~dB} \mathrm{~m}^{-1}$ for $433 \mathrm{MHz}$. Attenuation was hence slightly lower at $151 \mathrm{MHz}$ at the test site, and so this frequency was selected for use in the sensors.

\section{VALIDATION AND FIELD TESTING}

\subsection{Leverett Glacier}

In August 2012, testing of a prototype egg shell using $151 \mathrm{MHz}$ took place at a moulin $1.5 \mathrm{~km}$ from the margin of Leverett Glacier, to determine the impact of the cryoegg shell design on transmission performance. The cryoegg was lowered into the moulin on a rope tether so the depth of the egg could be determined. The strength of the received signal was recorded at varying horizontal distances from the moulin when the cryoegg was $30 \mathrm{~m}$ deep and submerged in a plunge pool at the base of the moulin. Finally, complete data transmissions from the prototype cryoegg were recorded at a range of distances $(0-2000 \mathrm{~m})$ from the target moulin and the signal decoded. The success of the signal
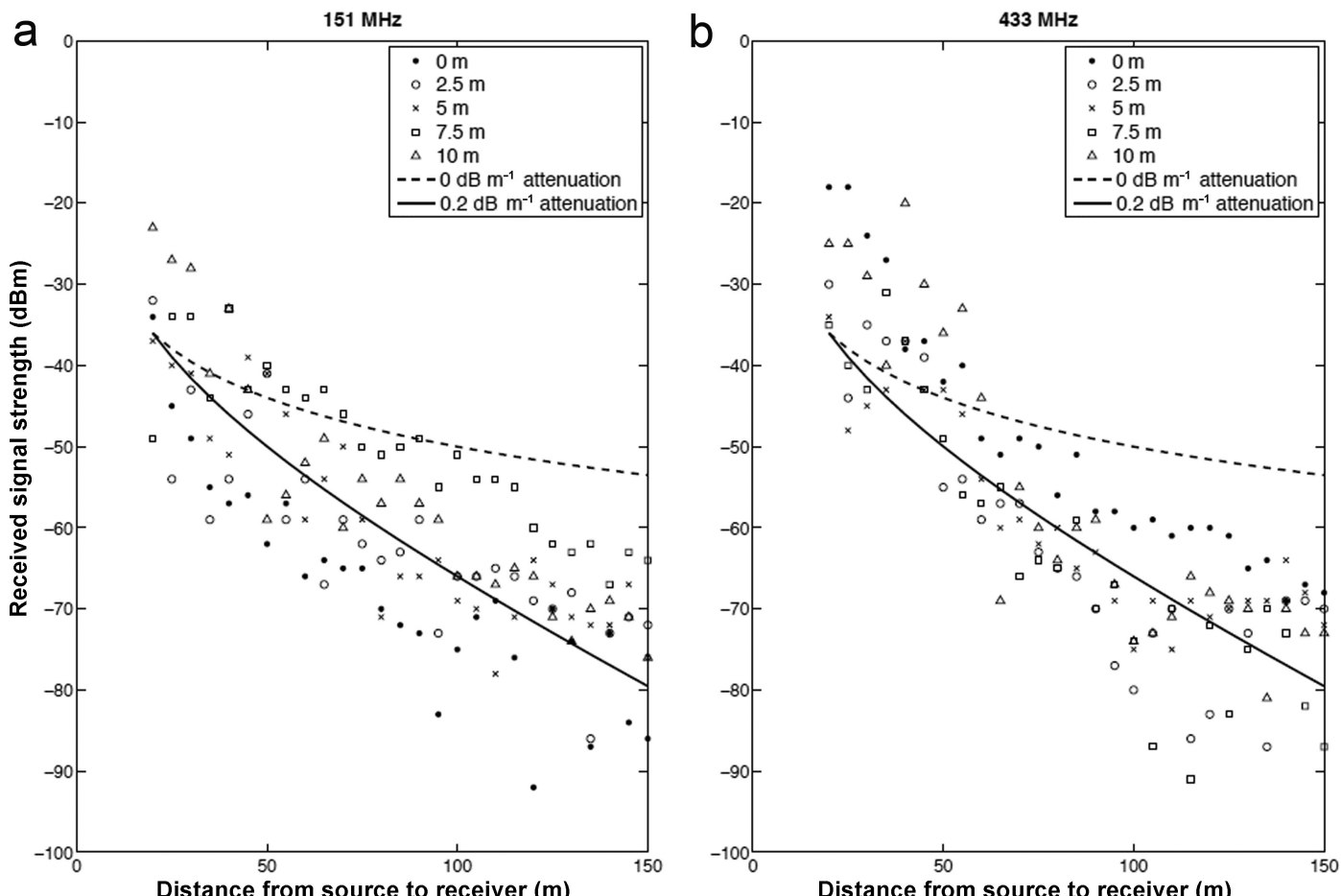

Fig. 3. Received RF signal strength from a transmitter lowered into a surface moulin. Results at $151 \mathrm{MHz}$ (a) and $433 \mathrm{MHz}$ (b). Markers show observations, and the different markers represent different depths to which the transmitter was lowered, as given in the legend. The dashed line shows the expected received signal with no attenuation, and the solid line shows the expected signal with $0.2 \mathrm{~dB} \mathrm{~m}^{-1}$ attenuation. 


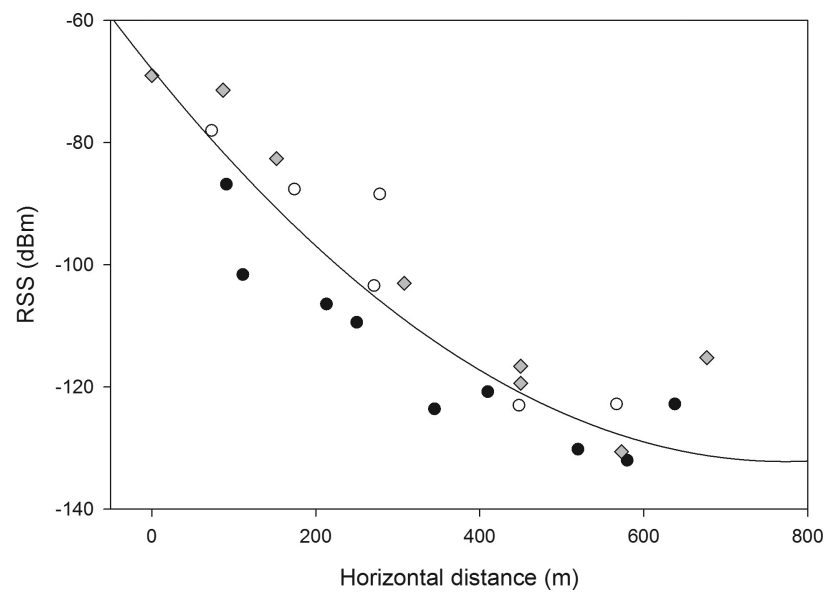

Fig. 4. Received RF signal strength from the cryoegg deployed $30 \mathrm{~m}$ below the ice surface. The different-shaped markers differentiate the three receiving transects collected in different directions from the moulin, and the fitting line is a polynomial quadratic fit $\left(r^{2}=0.85\right)$. The increase in RSS at $700 \mathrm{~m}$ is likely due to local topographic effects and is excluded from the quadratic fit.

decryption determined a maximum data transmission distance for the specific experimental set-up.

Some 23 ETracers were also released into a moulin $1.5 \mathrm{~km}$ from the margin of Leverett Glacier in August 2012, and their progress through the subglacial drainage was tracked via the periodic data transmissions to handheld receivers. Transmitted data were received by the WinRadio and Sika receivers situated on the hillside adjacent to the glacier, $1.6 \mathrm{~km}$ from the moulin entrance.

\subsubsection{Results}

In tests measuring the received signal strength (RSS) from the prototype cryoegg, RSS decreased with distance from the edge of the deployment moulin, and reached a minimum detectable threshold $(-140 \mathrm{dBm})$ at $600 \mathrm{~m}$ from the moulin (Fig. 4). To determine whether the signal passed through the ice or took a more tortuous path through the air, we measured the attenuation in air using the same equipment. When the signal travelled entirely through the air, there was little decrease in RSS with distance up to several $\mathrm{km}$ : the through-air path showed spreading, but little attenuation. By contrast, when the transmitters were below the ice, attenuation was significant, at $0.2 \mathrm{~dB} \mathrm{~m}^{-1}$, suggesting that the majority of the signal recorded travelled through ice not air. We therefore assume that increased horizontal distance from the moulin was equivalent to increased distance travelled through ice. The attenuation results were somewhat dependent on ice texture and surface morphology. In Figure 4, RSS actually increased slightly between 600 and $800 \mathrm{~m}$ distance because of a topographic feature. Full data transmissions (up to 240 s of continuous binary data) were accurately decoded up to $500 \mathrm{~m}$ from the moulin. Some data were recorded from $700 \mathrm{~m}$ distance, but they were noisy and there were gaps in the automated encryption. Additional data points could be deciphered manually, but we consider $500 \mathrm{~m}$ of wet ice the limit for reliable data reception. Figure 5 shows the $P$ and $T$ received during a 48 hour continuous deployment. The 4 hour data gap in the first 12 hours was due to a faulty receiver. The data show the cryoegg sinking into the plunge pool at the base of the moulin, reaching a depth of $8 \mathrm{~m}$ below the water surface, and then rising to an equilibrium

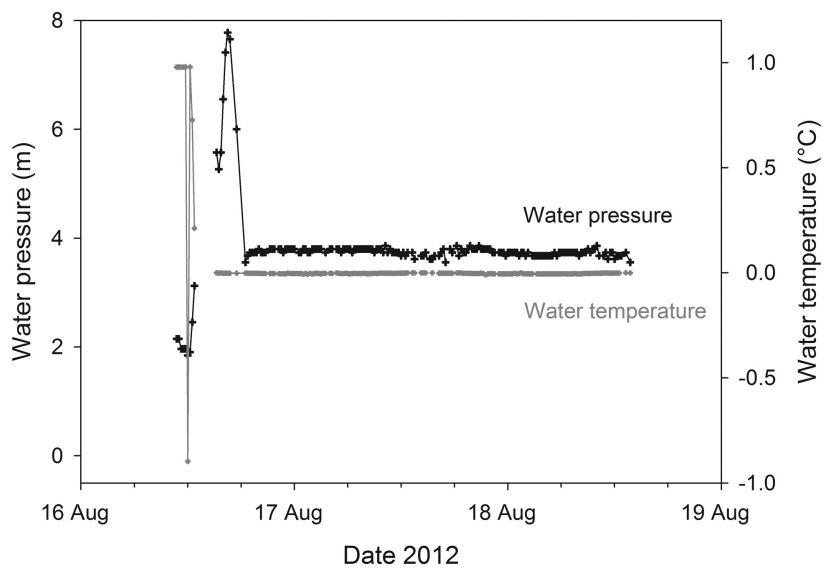

Fig. 5. Water pressure and temperature measured and transmitted by the cryoegg while deployed $30 \mathrm{~m}$ below the ice surface in a moulin. The data gap at the beginning of the time series is a result of a receiver malfunction, and the initial fluctuations in temperature and pressure show the egg descending into the moulin plunge pool before settling at an equilibrium depth $\sim 4 \mathrm{~m}$ below the waterline.

depth in a recirculating vortex $4 \mathrm{~m}$ below the water surface. There are small $(\mathrm{cm}$ scale) fluctuations in the water level over the next 48 hours, because of changing meltwater inputs and/or the cryoegg's motion within the plunge pool, but the water level and temperature remain broadly constant.

Data from the ETracers were audible up to $5 \mathrm{~km}$ away, when the majority of the signal travelled through air, and could be easily decrypted when the receiver was $1.6 \mathrm{~km}$ from the test moulin. The actual depth of the tracers during their transit was unknown. However, if we assume that they travelled through a subglacial channel rather than being routed englacially, data from the deepest ETracers had to travel through at least $100 \mathrm{~m}$ of ice (Chandler and others, 2013), several metres of water and then $>1 \mathrm{~km}$ of air to reach the receiver. Data were easily decipherable using either receiver, despite the low-powered transmitter. One ETracer passed all the way through the drainage system, travelling from the moulin $\sim 1.5 \mathrm{~km}$ from the ice-sheet margin to the glacier portal. The maximum water depth recorded was $43 \mathrm{~m}$ (Fig. 6a), from a sensor which passed all the way through the drainage system and exited the glacier at the portal. Another sensor reached $38 \mathrm{~m}$ (Fig. 6a).

Both receivers (WinRadio software radio and Sika radio tracking receiver) were able to record and decipher audio transmissions from the cryoegg and the ETracers. Data visualization was more straightforward with the WinRadio system, since the audio stream could be directly decoded on the attached PC. However, range was better with the Sika system: the data chirp was audible from a greater distance (up to $5 \mathrm{~km}$ away) than with the WinRadio (up to $2 \mathrm{~km}$ ). The WinRadio was advantageous for unattended operation since it could be controlled by a PC running in low-power mode, which also incorporated the data decryption GUI. Received data were saved to an internal memory card as either IF audio or decoded text files.

\subsection{Kiattuut Sermiat}

Additional testing of both sensor platforms was undertaken at Kiattuut Sermiat in August 2013. Five ETracers were released into crevasses, to determine meltwater depth and duration at 

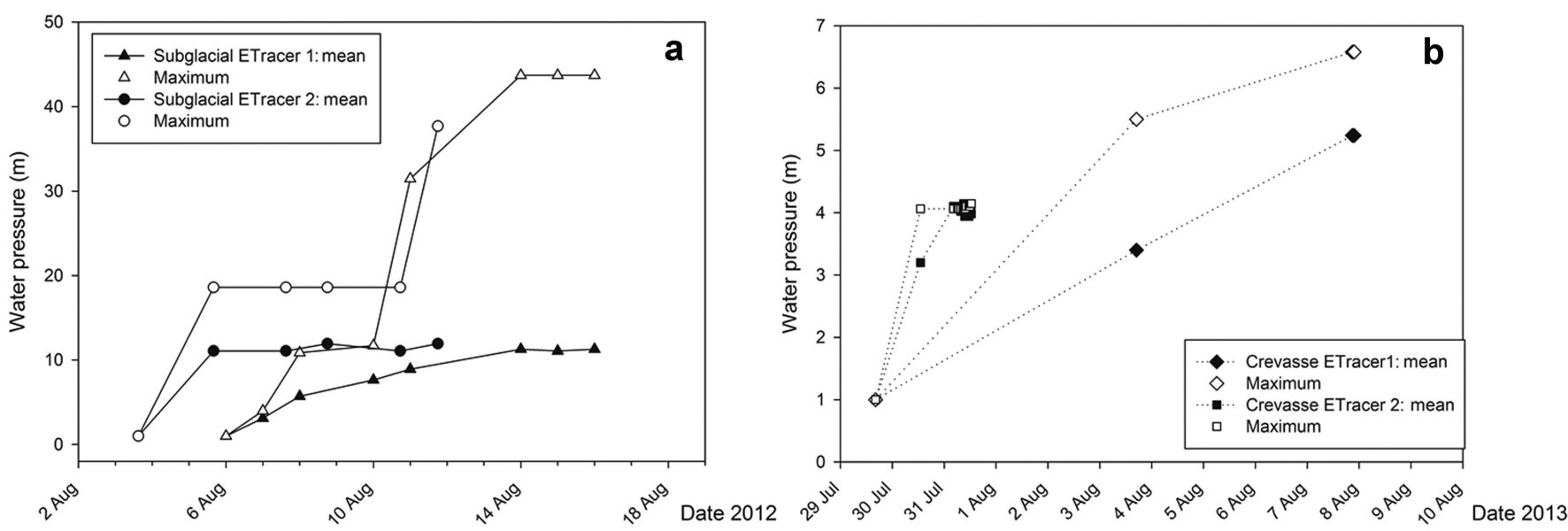

Fig. 6. Mean and maximum water pressure recorded and transmitted by ETracers in (a) subglacial drainage channels at Leverett Glacier and (b) crevasses at Kiattuut Sermiat.

the base of these features. Pressure readings were transmitted to an unmanned, solar-powered listening station comprising a WinRadio, horizontally mounted Yagi antenna and tablet PC $\sim 2 \mathrm{~km}$ from the crevasses. The cryoegg was deployed into a proglacial lake in front of Kiattuut Sermiat, in order to test the effectiveness of the RF transmission through sedimentladen water, and to test the longevity of the sensors in the field. Two cryoeggs were tethered in a mesh bag to the end of a rope, which was suspended from an inflatable kayak in the centre of the proglacial lake. The eggs were gradually lowered into the lake in turn, and the RSS was monitored at the receiving station $25 \mathrm{~m}$ away. Depth was measured by the length of rope paid out, and corroborated by the water pressure recorded by the cryoegg pressure sensors. One egg was then tethered to an ice outcrop in the centre of the proglacial lake at $12 \mathrm{~m}$ water depth (the probable base of the lake), where it remained for 20 days. The previous 24 hours of data were recorded each day at a set transmission time using the WinRadio and a netbook PC.

\subsubsection{Results}

Water-pressure measurements were transmitted and received from the ETracers in crevasses (Fig. 6b). Water was present in two of the monitored crevasses, with a

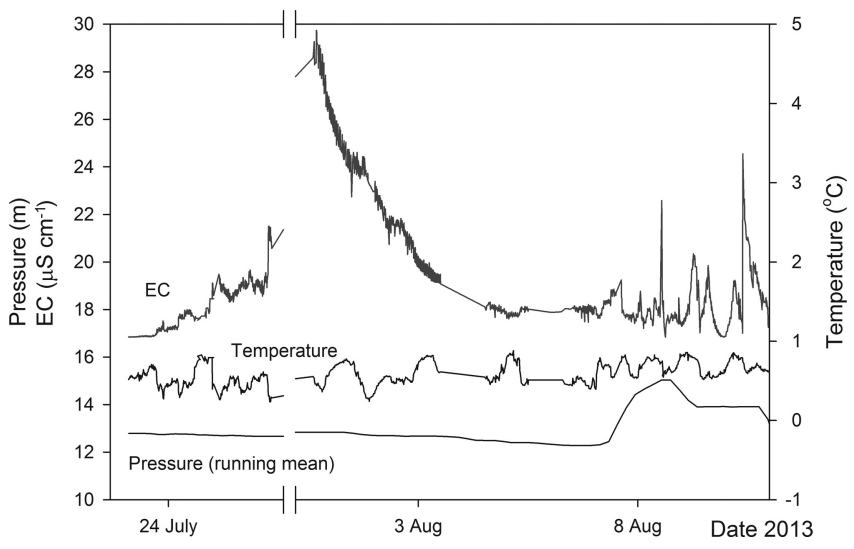

Fig. 7. Water pressure (running mean), temperature and EC recorded and transmitted from a cryoegg moored $12 \mathrm{~m}$ deep in a proglacial lake at Kiattuut Sermiat. The gaps in data (28-31 July, 4 and 6 August) occur because the receiver was in use elsewhere. maximum depth of $6.5 \mathrm{~m}$ up to 9 days after deployment. The unmanned listening station received and stored the data, either in IF or decoded numerical format. All three sensors on the cryoegg remained operational throughout the deployment. The data gap (28-31 July, Fig. 7) occurred because the receiver was in use elsewhere for 3 days; the egg remained functional. Comparison of the sensors on the egg with conventional EC sensors stationed $500 \mathrm{~m}$ downstream showed that a similar mean EC $\left(18 \mu \mathrm{Scm}^{-1}\right)$ was recorded by both sensors. The cryoegg was able to detect an outburst of solute-rich water at depth in the lake, indicated by the peak in EC (up to $29 \mu \mathrm{S} \mathrm{cm}^{-1}, 27$ July-3 August).

There was, however, significant signal attenuation within the proglacial lake water. RSS decreased by $10 \mathrm{~dB} \mathrm{~m}^{-1}$ $\left(r^{2}=0.85\right)$ in the two tests performed (Fig. 8), which was an order of magnitude higher than attenuation in ice. This did not have a negative impact on the ability to receive data from the egg, provided the receiver was not too far from the transmitter. Full transmissions were clearly audible with both receivers at $50 \mathrm{~m}$ distance, when the egg was moored at the base of the lake $\sim 12 \mathrm{~m}$ deep.

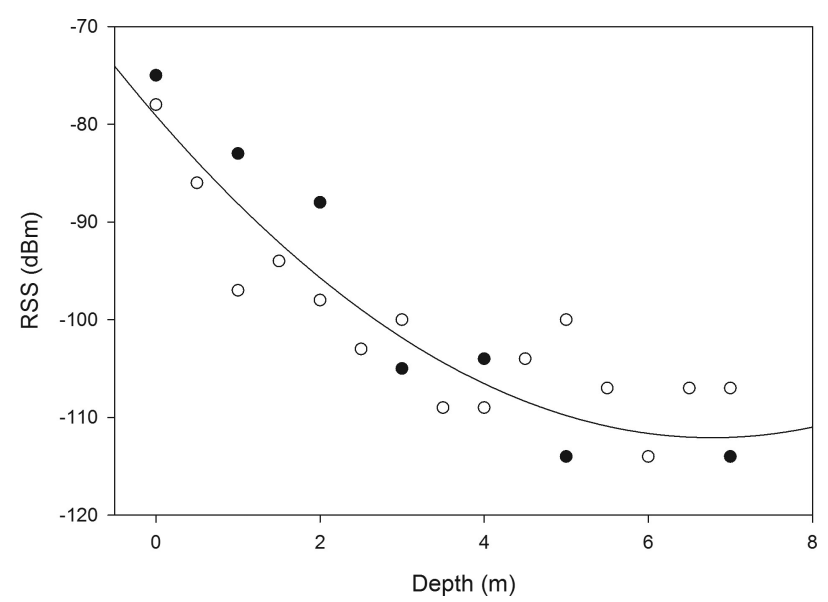

Fig. 8. Received RF signal strength from two cryoeggs (black or white markers) lowered into a proglacial lake, with polynomial quadratic fit $\left(r^{2}=0.85\right)$ showing that descent into sediment-filled water causes a tenfold decrease in RSS with distance when compared with horizontal distance through the ice (Fig. 4). The receiver was $25 \mathrm{~m}$ from the eggs. 


\section{DISCUSSION}

We set out to design two mobile sensor platforms for collecting data from subglacial meltwater environments: the small, mobile (and lower-cost) single-parameter ETracer, and the larger cryoegg which can support multiple sensors and transmit greater quantities of data. Both sensors were effective in the intended environment, in that all sensors remained operational during laboratory and field tests at low temperatures. The cryoegg was able to transmit continuous data from $27 \mathrm{~m}$ deep (including $4 \mathrm{~m}$ water) in a moulin, and through $12 \mathrm{~m}$ depth of water in a proglacial lake (Figs 5 and 7). The ETracers were able to transmit water pressure data from crevasses, and to travel into subglacial channels following deployment into moulins, from where they transmitted water pressure data through the ice (Fig. 6). One ETracer emerged from the glacier portal after 10 days in the subglacial drainage system.

Data sent by the ETracers were used to determine effective pressure (Shreve, 1972) in the lower regions of Leverett Glacier. Cryostatic pressure at the moulins 1-2 km from the glacier margin was calculated by Eqn (2), where $P_{\mathrm{i}}$ is ice pressure, $\rho_{\mathrm{i}}$ is the density of ice $\left(917 \mathrm{~kg} \mathrm{~m}^{-3}\right), g$ is gravitational acceleration $\left(9.81 \mathrm{~m} \mathrm{~s}^{-2}\right), H$ is the altitude of the ice surface and $z$ is the elevation of the point in question. The effective pressure in the moulins $(N)$ was calculated by comparing $P_{\mathrm{i}}$ to the measured water pressure $\left(P_{\mathrm{w}}\right.$, Eqn (3)).

$$
\begin{gathered}
P_{\mathrm{i}}=\rho_{\mathrm{i}} g(H-z) \\
N=P_{\mathrm{i}}-P_{\mathrm{w}}
\end{gathered}
$$

The mean pressure measured by the ETracers resulted in positive values of $N$, indicating a propensity for channel closure via creep (Walder and Fowler, 1994) and unpressurized channels. This agrees with estimates of the regions of high and low subglacial water pressures conducted via dye and gas tracing, which also showed that the lower $7 \mathrm{~km}$ of the ice sheet was not pressurized (Chandler and others, 2013). However, the maximum pressure recorded (Fig. 6a), $\sim 11$ days after the tracer was released into the drainage system, shows that there was a limited region where $P_{\mathrm{w}} \geq P_{\mathrm{i}}$. We suspect that even in the lower regions of the Greenland ice sheet, there are small regions where high water pressure exists in subglacial channels because of short-term perturbations (Meierbachtol and others, 2013), particularly at the height of the ablation season and in years with exceptionally high surface melt (Tedstone and others, 2013). Our limited data should not be extrapolated beyond the region of measurement, but do demonstrate that in situ measurements are valuable for model validation, and that these wireless sensors demonstrate a simple, effective method for determining local subglacial water pressure in regions with active moulins.

RF was an effective method of data transmission, as has previously been demonstrated by similar systems (Hart and others, 2006; Smeets and others, 2012), and it was successful in both ice and meltwaters. Attenuation was higher in water than in ice (Figs 4 and 8), but data were still audible through $12 \mathrm{~m}$ of sediment-rich water (mean suspended sediment $0.1 \mathrm{~g} \mathrm{~L}^{-1}$ ) when the receiver was $25 \mathrm{~m}$ from the cryoegg. The best results were obtained when the transmitter and receiver were in close proximity, and RSS decreased when the distance between them increased. For the ice tests, the relationship between distance and RSS was not linear (Figs 2-4). The signal travelled through ice, air, sediment and water before it reached the receiver, and it was impossible to determine which path the signal actually took. The most direct path in our tests was through the ice, and the signal experienced attenuation rather than spreading alone, so we assume that this pathway is preferential. The small variations between tests can therefore be explained by undulations in the local terrain which changed the actual through-ice distance that the signal travelled before reaching the receiver, or by minor variations in the orientation of transmitter and directional receiving antenna.

Attenuation results were significantly higher than those found in the literature for attenuation in deep Antarctic ice, which range from -1 to $-40 \mathrm{~dB} \mathrm{~km}^{-1}$ (Barwick and others, 2005; Matsuoka and others, 2012). This is because the nearsurface ice in our experimental regions was warm (hence has a high water content) and inhomogeneous compared to deeper ice. The results are more similar to those observed on the Ross Ice Shelf, Antarctica, where attenuation depth was $300-500 \mathrm{~m}$ at $75-1250 \mathrm{MHz}$ (Barrella and others, 2011). Our experiments predict that signal attenuation in nearsurface Greenland ice is of the order of $200 \mathrm{~dB} \mathrm{~km}^{-1}$ (Fig. 3), which limits the cryoegg transmission distance to just over $500 \mathrm{~m}$. This was confirmed by tests of the prototype cryoegg which transmitted the complete dataset $40 \mathrm{~s}$ of data at $300 \mathrm{bps}$ ): clear reception and reliable data decryption were possible up to $500 \mathrm{~m}$ from the moulin where the cryoegg was submerged, but quality decreased when this distance was exceeded.

Deeper ice is likely to be colder and more homogeneous, and hence have attenuative characteristics more similar to estimates of $<40 \mathrm{~dB} \mathrm{~km}^{-1}$ attenuation recorded elsewhere in the Antarctic (Matsuoka and others, 2012). Based on this evidence, we predict that the cryoegg range will be extended if used in deeper ice. The performance of the cryoegg transmission is similar to the WiSe system demonstrated by Smeets and others (2012) which uses HF radio. Here very good-quality data were transmitted from $600 \mathrm{~m}$ beneath the surface at the K-Transect in South Greenland, which begins a few kilometres north of our test moulins and hence has similar ice properties. Deeper transmissions $(2500 \mathrm{~m})$ were successful at the NEEM (North Greenland Eemian Ice Drilling) site near the ice divide, where ice is thick, cold and uniform. The WiSe remained tethered and the receiving station was fixed.

The cryoegg and ETracer receivers are portable, allowing data collection from either a handheld, roving unit or a fixed, automated listening station. Data reception was improved when the receiver was located at an elevated location, either on an ice rise or on the glacier side-walls, which enabled reception of data from the ETracers when they were beneath $\sim 100 \mathrm{~m}$ ice and the receiver was $1.6 \mathrm{~km}$ away. When selecting a site for the receiver, a compromise between distance from the transmitter and elevation must be reached for the best signal. In long-term deployments, the antenna could be elevated above the glacier surface on a permanent mount, rather than being hand-carried. Permanent base stations have been successful in both the Glacsweb and WiSe subglacial sensor deployments (Hart and others, 2006; Smeets and others, 2012). However, a permanent station potentially limits the range of the system when the sensor platform is mobile and able to move through subglacial water channels. In an ideal scenario, several receivers would be sited within range of the roving 
sensor, allowing the closest station to receive data. Networking of such base stations is also an option (Martinez and others, 2004; Murray and O'Farrell, 2013).

Our laboratory and field tests demonstrate that the cryoegg and ETracers are effective wireless sensor platforms for use in sub-ice hydrological systems including those found beneath glaciers. The ETracers can pass through subglacial meltwater channels, and are useful in monitoring heavily crevassed areas: sensors can be deployed into hazardous regions without endangering personnel, and could potentially reveal important information about fracture propagation and calving processes (Hanson and Hooke, 2000; Weiss, 2004; Logan and others, 2013). The cryoegg is suitable for transmitting data through ice and water, and can support several on-board sensors. The proglacial lake test demonstrates their potential for use in lake monitoring (e.g. in early-warning systems for lakes prone to glacial lake outburst floods (Richardson and Reynolds, 2000; Fukui and others, 2008)). The maximum transmission range $(500 \mathrm{~m})$ is likely to increase in colder, drier and more uniform ice, so the cryoegg sensor platform is a plausible technology for in situ measurement of subglacial water bodies.

\section{CONCLUSIONS}

The cryoeggs and ETracers are versatile wireless sensor platforms for use in glacial environments. The customdesigned shells can withstand high pressure, impact, abrasion and turbulent flows while allowing the on-board sensors to make contact with meltwater. They are specifically designed for wireless, tether-free operation, and can be deployed into the subglacial environment via moulins, from where they are free to flow into subsurface melt channels. The smaller-diameter ETracer was particularly effective in this role. Test deployments in moulins and in a proglacial lake at the margins of the Greenland ice sheet showed that the cryoegg can take measurements in meltwater and transmit data through up to $500 \mathrm{~m}$ of wet, nonuniform ice to receivers up to $2 \mathrm{~km}$ away. We predict that the transmission distance will be greater when the signal travels through colder, more uniform ice. The lower-powered and lower-cost ETracers could transmit through at least $100 \mathrm{~m}$ of ice to receivers $1.6 \mathrm{~km}$ away, and were able to return water pressure data from subglacial channels and crevasses. The data showed that the marginal subglacial drainage system of Leverett Glacier was generally unpressurized, in agreement with estimates from dye and gas tracing, but there was a small area where water pressure in the subglacial channel exceeded ice overburden pressure. They also demonstrated that between 1 and $6.5 \mathrm{~m}$ water was present in some crevasses in the lower $3 \mathrm{~km}$ of Kiattuut Sermiat. The use of $\mathrm{VHF}$ for transmission means that the receiving antennas are portable, and off-the-shelf components can be utilized. The receiving units are small, flexible and inexpensive, and can either be hand-carried or mounted on a semi-permanent listening station. The payload of both sensor platforms is flexible, and there is capacity for several sensors on board the cryoegg. The prototype unit contained water-pressure, temperature and EC sensors, all of which performed well in cold, low-ionic-strength waters. The tests demonstrate that roaming wireless sensors have the potential to reveal important processes occurring in otherwise inaccessible glacial hydrologic environments.

\section{ACKNOWLEDGEMENTS}

This work was supported by UK Natural Environment Research Council (NERC) grants NE/D007321/1 and NE/ H023879/1. Fieldwork was enabled by HeliGreenland, Kangerlussuaq International Science Support, Blue Ice Explorer Narsarsuaq, and enthusiastic and helpful field assistants from the University of Bristol. Chung-Seng Ling and the Queens School of Engineering workshop assisted in the manufacture of the cryoegg shells, and two reviewers suggested valuable improvements to the manuscript.

\section{REFERENCES}

Bagshaw EA and 7 others (2012) E-tracers: development of a low cost wireless technique for exploring sub-surface hydrological systems. Hydrol. Process., 26(20), 3157-3160 (doi: 10.1002/ hyp.9451)

Barrella T, Barwick S and Saltzberg D (2011) Ross Ice Shelf (Antarctica) in situ radio-frequency ice attenuation. J. Glaciol., 57(201), 61-76 (doi: 10.3189/002214311795306691)

Bartholomew I and 6 others (2011) Supraglacial forcing of subglacial drainage in the ablation zone of the Greenland ice sheet. Geophys. Res. Lett., 38(8), L08502 (doi: 10.1029/ 2011GL047063)

Barwick S, Besson D, Gorham P and Saltzberg D (2005) South Polar in situ radio-frequency ice attenuation. J. Glaciol., 51(173), 231-238 (doi: 10.3189/172756505781829467)

Behar A and 8 others (2008) The moulin explorer: a novel instrument to study Greenland ice sheet melt-water flow. [Abstr. C11A-0475] Eos, 89, Fall Meet.

Blake EW, Fischer UH and Clarke GKC (1994) Direct measurement of sliding at the glacier bed. J. Glaciol., 40(136), 595-599

Chandler DM and 11 others (2013) Evolution of the subglacial drainage system beneath the Greenland Ice Sheet revealed by tracers. Nature Geosci., 6(3), 195-198 (doi: 10.1038/ngeo1737)

Christner BC, Montross GG and Priscu JC (2012) Dissolved gases in frozen basal water from the NGRIP borehole: implications for biogeochemical processes beneath the Greenland Ice Sheet. Polar Biol., 35(11), 1735-1741 (doi: 10.1007/s00300012-1198-z)

Doyle SH and 9 others (2013) Ice tectonic deformation during the rapid in situ drainage of a supraglacial lake on the Greenland Ice Sheet. Cryosphere, 7(1), 129-140 (doi: 10.5194/tc-7-129-2013)

Engelhardt $\mathrm{H}$ and Kamb B (1998) Basal sliding of Ice Stream B, West Antarctica. J. Glaciol., 44(147), 223-230

Engelhardt H, Humphrey N, Kamb B and Fahnestock M (1990) Physical conditions at the base of a fast moving Antarctic ice stream. Science, 248(4951), 57-59 (doi: 10.1126/ science.248.4951.57)

Evans S (1963) Radio techniques for the measurement of ice thickness. Polar Rec., 11(73), 406-410

Fountain AG, Jacobel RW, Schlichting R and Jansson P (2005) Fractures as the main pathways of water flow in temperate glaciers. Nature, 433(7026), 618-621 (doi: 10.1038/nature03296)

Fukui H, Limlahapun P and Kameoka T (2008) Real time monitoring for Imja Glacial Lake in Himalaya - global warming front monitoring system. In Proceedings of Society of Instrument and Control Engineers (SICE) Annual Conference, 20-22 August 2008, Tokyo, Japan. Society of Instrument and Control Engineers, Tokyo, 2578-2581

Gulley JD, Benn DI, Screaton E and Martin J (2009) Mechanisms of englacial conduit formation and their implications for subglacial recharge. Quat. Sci. Rev., 28(1920), 1984-1999 (doi: 10.1016/ j.quascirev.2009.04.002)

Gulley JD, Walthard P, Martin J, Banwell AF, Benn DI and Catania G (2012) Conduit roughness and dye-trace breakthrough curves: why slow velocity and high dispersivity may not reflect flow in 
distributed systems. J. Glaciol., 58(211), 915-925 (doi: 10.3189/ 2012JoG11J115)

Haldorsen S (1981) Grain-size distribution of subglacial till and its relation to glacial crushing and abrasion. Boreas, 10(1), 91-105

Hanson B and Hooke RLeB (2000) Glacier calving: a numerical model of forces in the calving-speed/waterdepth relation. J. Glaciol., 46(153), 188-196 (doi: 10.3189/ 172756500781832792)

Harper JT and Humphrey NF (1995) Borehole video analysis of a temperate glacier's englacial and subglacial structure: implications for glacier flow models. Geology, 23(10), 901-904

Hart JK, Martinez K, Ong R, Riddoch A, Rose KC and Padhy P (2006) A wireless multi-sensor subglacial probe: design and preliminary results. J. Glaciol., 51(178), 389-397 (doi: 10.1111/ j.1365-3091.2005.00758.x)

Hart JK, Rose KC, Waller RI, Vaughan-Hirsch D and Martinez K (2011) Assessing the catastrophic break-up of Briksdalsbreen, Norway, associated with rapid climate change. J. Geol. Soc. London, 168(3), 673-688 (doi: 10.1144/0016-76492010-0)

Hubbard BP, Sharp MJ, Willis IC, Nielsen MK and Smart CC (1995) Borehole water-level variations and the structure of the subglacial hydrological system of Haut Glacier d'Arolla, Valais, Switzerland. J. Glaciol., 41(139), 572-583

Iken A and Bindschadler RA (1986) Combined measurements of subglacial water pressure and surface velocity of Findelengletscher, Switzerland: conclusions about drainage system and sliding mechanism. J. Glaciol., 32(110), 101-119

Kor PSG, Shaw J and Sharpe DR (1991) Erosion of bedrock by subglacial meltwater, Georgian Bay, Ontario: a regional view. Can. J. Earth Sci., 28(4), 623-642

Lanoil B and 7 others (2009) Bacteria beneath the West Antarctic Ice Sheet. Environ. Microbiol., 11(3), 609-615 (doi: 10.1111/ j.1462-2920.2008.01831.x)

Lishman B and 6 others (2013) Assessing the utility of acoustic communication for wireless sensors deployed beneath ice sheets. Ann. Glaciol., 54(64), 124-134 (doi: 10.3189/2013AoG64A022)

Logan L, Catania G, Lavier L and Choi E (2013) A novel method for predicting fracture in floating ice. J. Glaciol., 59(216), 750-758 (doi: 10.3189/2013JoG12J210)

Martinez K and Basford P (2011) Robust wireless sensor network performance analysis. In Proceedings of IEEE Sensors Conference 2011, 28-31 October, Limerick, Ireland. Institute of Electrical and Electronics Engineers, Piscataway, NJ, 203-206

Martinez K, Hart JK and Ong R (2004) Environmental sensor networks. IEEE Computer, 37(8), 50-56 (doi: 10.1109/ MC.2004.91)

Matsuoka K, MacGregor JA and Pattyn F (2012) Predicting radar attenuation within the Antarctic ice sheet. Earth Planet. Sci. Lett., 359-360, 173-183 (doi: 10.1016/j.epsl.2012.10.018)

Meierbachtol T, Harper J and Humphrey N (2013) Basal drainage system response to increasing surface melt on the Greenland Ice
Sheet. Science, 341(6147), 777-779 (doi: 10.1126/ science.1235905)

Murray T and O'Farrell T (2013) Monitoring glacier calving using a wireless network of GNSS sensors at Helheim Glacier, SE Greenland: initial results. In NERC Networks of Sensors Annual Showcase Technology Event, 6 December 2013, London, UK https://www.innovateuk.org/web/network-of-sensors/ what-we-do

Nienow P, Sharp M and Willis I (1998) Seasonal changes in the morphology of the subglacial drainage system, Haut Glacier d'Arolla, Switzerland. Earth Surf. Process. Landf., 23(9), 825-843 (doi: 10.1002/(SICl)1096-9837(199809)23:9 $<825:$ :AID-ESP893>3.0.CO;2-2)

Oswald GKA and Gogineni SP (2008) Recovery of subglacial water extent from Greenland radar survey data. J. Glaciol., 54(184), 94-106 (doi: 10.3189/002214308784409107)

Peters ME, Blankenship DD and Morse DL (2005) Analysis techniques for coherent airborne radar sounding: application to West Antarctic ice streams. J. Geophys. Res., 110(B6), B06303 (doi: 10.1029/2004JB003222)

Priscu JC and 11 others (1999) Geomicrobiology of subglacial ice above Lake Vostok, Antarctica. Science, 286(5447), 2141-2144 (doi: 10.1126/science.286.5447.2141)

Richardson SD and Reynolds JM (2000) An overview of glacial hazards in the Himalayas. Quat. Int., 65-66(1), 31-47 (doi: 10.1016/S1040-6182(99)00035-X)

Shreve RL (1972) Movement of water in glaciers. J. Glaciol., 11(62), 205-214

Skidmore ML, Foght JM and Sharp MJ (2000) Microbial life beneath a high Arctic glacier. Appl. Environ. Microbiol., 66(8), 3214-3220 (doi: 10.1128/AEM.66.8.3214-3220.2000)

Smeets CJPP and 6 others (2012) A wireless subglacial probe for deep ice applications. J. Glaciol., 58(211), 841-848 (doi: 10.3189/2012JoG11J130)

Tedstone AJ and 6 others (2013) Greenland ice sheet motion insensitive to exceptional meltwater forcing. Proc. Natl Acad. Sci. USA (PNAS), 110(49), 19719-19724 (doi: 10.1073/ pnas.1315843110)

Walder JS and Fowler A (1994) Channelized subglacial drainage over a deformable bed. J. Glaciol., 40(134), 3-15

Weertman J (1972) General theory of water flow at the base of a glacier or ice sheet. Rev. Geophys., 10(1), 287-333

Weiss J (2004) Subcritical crack propagation as a mechanism of crevasse formation and iceberg calving. J. Glaciol., 50(168), 109-115 (doi: 10.3189/172756504781830240)

Willis IC (1995) Intra-annual variations in glacier motion: a review. Progr. Phys. Geogr., 19(1), 61-106 (doi: 10.1177/ 030913339501900104)

Zirizzotti A, Urbini S, Cafarella L and Baskaradas JA (2010) Radar systems for glaciology. In Kouemou G ed. Radar technology. InTech, Rijeka (doi: 10.5772/7179) 